This item was submitted to Loughborough's Research Repository by the author.

Items in Figshare are protected by copyright, with all rights reserved, unless otherwise indicated.

\title{
What is 'Value' and how can we capture it from the product value chain?
}

PLEASE CITE THE PUBLISHED VERSION

http://www.springer.com/gb/book/9789811004698

\section{PUBLISHER}

(C) Springer

VERSION

AM (Accepted Manuscript)

\section{PUBLISHER STATEMENT}

This work is made available according to the conditions of the Creative Commons Attribution-NonCommercialNoDerivatives 4.0 International (CC BY-NC-ND 4.0) licence. Full details of this licence are available at: https://creativecommons.org/licenses/by-nc-nd/4.0/

\section{LICENCE}

CC BY-NC-ND 4.0

\section{REPOSITORY RECORD}

Lee, Jacquetta, J. Suckling, Debra Lilley, and Garrath T. Wilson. 2019. "What Is 'value' and How Can We Capture It from the Product Value Chain?". figshare. https://hdl.handle.net/2134/26402. 


\title{
What is 'value' and how can we capture it from the product value chain?
}

\author{
Jacquetta Lee ${ }^{1}$, James R. Suckling ${ }^{1}$, Debra Lilley ${ }^{2}$, Garrath T. Wilson ${ }^{2}$ \\ ${ }^{1}$ Centre for Environmental Strategy, University of Surrey, Guildford, UK \\ ${ }^{2}$ Loughborough Design School, University of Loughborough, Loughborough, UK
}

\begin{abstract}
The mobile phone industry is based upon the rapid development of handsets and the high turnover of devices in order to drive sales. Phones are often used for shorter periods of time than their designed life and when discarded it is often through channels that result in lost resource. This unsustainable business model places strain on resources and creates adverse environmental and social impacts. Through interrogation of a stocks and flows model, a product-service system (PSS) for a small consumer electronic device, a mobile telephone is proposed. The points at which value may be extracted from the PSS are identified. A quantitative measure of value is proposed in order to allow the evaluation of the most appropriate time to extract it. This value is not solely monetary, but is derived from the combination of indicators which encompass environmental, economic and technological factors. A worked example is presented, in which it is found that the precious metals within the phone are the main determinants for value extraction. These metals are found in the printed circuit board, leading to a requirement to design phones for ease of extraction of these components in order to access the value within.
\end{abstract}

\section{INTRODUCTION}

The mobile phone has become a ubiquitous technology which the consumer has embraced as part of their everyday lives with enthusiasm. From their introduction in the early $1980 \mathrm{~s}$, the mobile phone has undergone a constant and rapid development, increasing in processing power and device capability whilst reducing in physical size. However, their swift advancement has led to a legacy of waste and lost resource in which consumers are incentivised to replace their phones before an end of life driven by product failure and absolute obsolescence [1]. Furthermore, the high turnover of phones is exacerbated by the lack of drivers to return phones through appropriate channels for recycling [2]. Instead, the old, replaced phones are often kept by the consumer and left unused in storage, or hibernation [3]. At the start of hibernation the mobile phones have a technological and monetary value which could be extracted through reuse in secondary markets, but at the end of hibernation, they have often decreased in value so much as to be worthless to the consumer and business [4]. Due to their small size, many often end up in landfill, their value essentially lost. The situation may be further exacerbated when phones are sold for reuse: they may be sold or donated to lower value markets in developing countries where the recycling infrastructure is not in place to allow for effective collection at end of life [5].

All of the above factors combine to create a leakage of precious resource and a loss of value during the products potential useful lifetime as well as a negative environmental and social impact, from pollution from landfill and the constant need to replace the materials from virgin sources, when recycling would be more environmentally efficient [6].

This paper will explore the value contained in phones and what 'value' means in the context of developing a sustainable product-service system business model. Further discussion will be given on the methods which may be used to maximize the capture of value and at what stages of the product's life cycle it can be best extracted.

\section{STOCKS AND FLOWS}

\subsection{A system-based approach}

The current mobile phones business model is built around the concept of maximising flows; producing and selling as many handsets as possible within a given period of time. The more phones a business can sell, the more successful it is. This flow can broadly be defined as the movement of handsets from the manufacturer, through the consumer(s) to the eventual disposal route, e.g. land fill or recycling. With consumer demand typically satiated by replacement with a new handset that has been manufactured by mining evermore virgin material and with relatively few phones returned for recycling, resource is commonly lost at the end of the life cycle [7][2]. This is not a resource efficient business model and in a world with finite size and mineral reserve, this is clearly not a sustainable solution. In Europe the Waste Electrical and Electronic Equipment (WEEE) Directive [8] has gone some way to alleviate the flow of electronic waste to landfill, but it is not perfect, with loopholes being exploited to enable export of waste to markets with informal recycling [9], creating deleterious implications for environmental and human toxicity [10]. 
An alternative approach to improving resource efficiency is to consider a system based upon maintaining the quality and quantity of stocks [11]. In this approach the phones in use are considered a stock which must be maintained through the careful management of flows around the system in order that they are utilised most effectively for an appropriate length of time. The stock is maintained at sufficient quality by multiple levels of intervention, for example reusing the stock as is, without modification, if it is still able to perform its function adequately. Reuse of whole phones can be supplemented by reuse of components and remanufacture of phones to optimise the effective time that each part may be used. Finally, recycling the materials to ensure closure of the economy can reduce the burden on virgin stock by minimising extraction.

Fig. 1 shows a possible mobile phone stock and flow diagram. The stock of phones, $S$, is maintained for a time period, $T$, by channelling the phones returned to the manufacturer through the reuse or remanufacture loops. Those that cannot be reused are sent for component value assessment and disassembly. Parts of the phone that may be reused are directed to a stockpile of components, whereas those that cannot are reprocessed and recycled. The recycled material is fed back into the manufacturing process and used to reduce, but not eliminate, the quantity of virgin material required: the mobile phone market is growing, plus the recycling loop is dissipative, so there will always be a requirement for additional 'new' flows into this system. However, this new systemic approach should minimise this resource burden. Given the technological advance of mobile phones, the stockpile of components will only have a given shelf-life before becoming obsolete. Once obsolete, they too are returned for reprocessing and recycling or possibly exported to a lower value market in which they still have worth. At all steps there will be inevitable waste which exits the system (dashed lines). The waste is seen as an imbalance in the flows into and out of the stock. An example of this is the waste flow from remanufacture; the waste is the components which are replaced. A flow of equal magnitude is required from the stockpile of components to balance this out.

If a strategy of prioritising virgin stock use is pursued, with reprocessed material making up the shortfall in supply, the effort in reusing the components becomes disproportionate. This leads to a simplified version of Fig. 1 in which the obsolete stock feeds directly into the reprocessing.

Additionally, each pool of stock requires an intervention, denoted by an $i$ (blue text), in order to be maintained. These interventions take the form of input into the stock, such as labour or energy, and emissions, for example the greenhouse gases associated with energy production. At each point the appropriate level of intervention must be calculated to ensure an efficient use of the stock.
The flow of stock is divided at certain points into fractional flows. These fractions are indicated by the parameters, $f_{1}, f_{2}$ etc. Each of the fractions are dictated by the stock into which the flow is feeding. For example, the flow of material into the manufacturing process from mining virgin material, $\left(1-r_{2}\right)\left(1-r_{1}-u_{1}\right) p$, is dictated by the difference between the flow required to maintain the stock, $\left(1-r_{1}-u_{1}\right) p$ and the supply of reprocessed and recycled stock available, $r_{2}\left(1-r_{1}-u_{1}\right) p$. The assessment of the fractional flows between the stocks leads to an understanding of the sustainability of the entire system. To achieve a targeted sustainable level may itself lead to the definition of desired values for $f_{i}, r_{i}$ and $u_{i}$.

\subsection{Product-service systems and stocks and flows}

PSSs provide a business model whereby the function or value that satisfies consumer needs becomes the focus of business moving away from "designing (and selling) physical products only, to designing (and selling) a system of products and services which are jointly capable of fulfilling specific client demands" [12]. As illustrated in the PSS proposed by Wilson et al. [13], it is not necessary that the hardware of an electronic device be owned by the consumer, indeed, the hardware, including circuit boards (PCBs), chips (ICs) and other electronic components, can be leased as part of a service to the consumer due to their low intrinsic emotional value. The emphasis of the PSS and the system, therefore, can shift from producing more hardware towards maintaining the hardware in use, which may be regarded as one method of retaining the quality and quantity of the stock. Logically, the most effective businesses operating PSSs are the ones that can provide the service with the most efficient maintenance possible, therefore, PSSs are suited to the stocks and flows model through their use of effective design to ensure reliability, ease of maintenance, reuse and remanufacture of devices through the carefully planned application of labour.

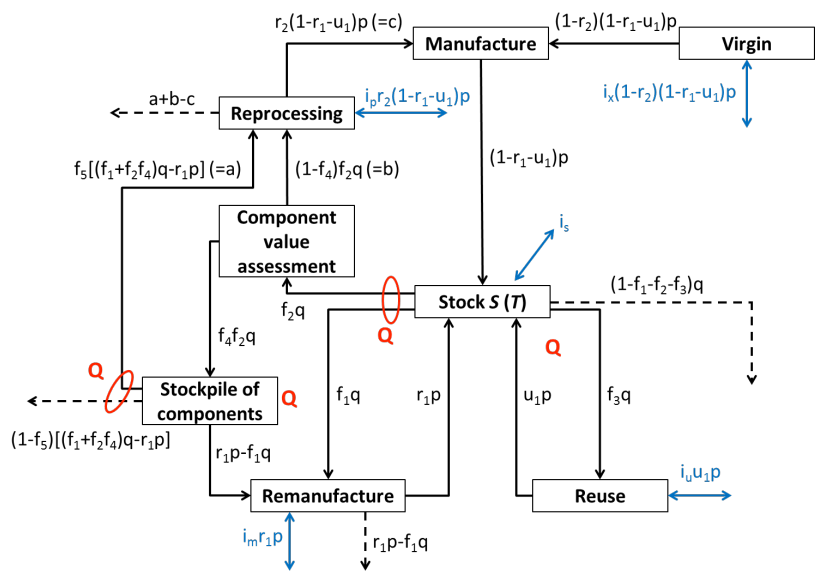

Fig. 1 Stocks and flows system of a mobile phone.

The analysis of an effective stock and flow model can inform the development of a PSS by identifying the points in the process where a decision must be made and hence 
the behaviour of the participants in the PSS. A decision is distinct from an intervention: the latter is an impact incurred through maintaining the stock; the former dictates through which channel the flow is directed. The decision points are indicated in Fig. 1 by red Q's. The decision points will not only inform and shape the consumer interaction with the service, but will also inform and direct the flow of components through the loop which will allow the best extraction of value.

In order to make the best decision possible, the sustainable value of the phone and constituent components must be understood at points in both the stock and flow model, and also time. The decisions become the comparison of the sustainable value against predefined thresholds. This is addressed later in this article.

\subsection{Hierarchy of sustainability}

There is a hierarchy of preferred routes within those shown in Fig. 1. The closer that the phones and components can remain in form to the stock, $S$, the more sustainable the system. Reusing the phones without modification is preferable to remanufacture, which is itself preferable to complete dismantling in order to recover the components and materials. This leads to a hierarchy which will enable keeping the flow as close to the stock as possible. As such prioritisation should be to:

1. Increase $T$ : time spent where the phone fulfils its designed functions to a level required by the market, in order to reduce $p$.

2. Increase reuse, $f_{3}$.

3. Increase remanufacture, $f_{l}$.

4. Increase stockpile, $f_{4}$.

5. Increase reprocessing after stockpiling, $f_{5}$.

6. Reduce inputs into manufacture, $i_{m}$.

If desired the list may be extended further to include ever more incremental advantages.

\subsection{Value and thresholds}

In order to control the flow of phones and components around the system, the decision points are used to affect the routing of a particular flow. The decisions relate to the ability of the complete phone or the components within it to perform a function within the stock and flow system as a whole. Therefore, it is proposed that at each decision point a threshold must be set against which the items are assessed. If they meet this threshold, they are directed along one particular route, or along the other if they do not. In order to set the threshold and assess the worth of an item, it must be assigned a value and that value assessed at that point in the flow at a given time. The assessment of value at given points in the flow system will inform the creation of a PSS and its interaction points with the consumer.

\section{UNDERSTANDING VALUE}

In order to extract most value from the stocks and flows at the most appropriate juncture, it is necessary to have a thorough understanding of the value embodied within the phones and components at any given moment in time. The assessment of value will be used at each of the identified decision points in the stocks and flows system as well as to help in defining the consumers' touch points.

The term value has been used in this article much already, but it may mean many different things to different people, thus it is necessary to provide a definition of value for this work. The main consideration of value in typical productorientated business models at present is given towards the economic value that can be extracted. This gives no consideration to the indefinite sustainability of the business into the future. To that extent other key values are ignored. For example the value of retaining a certain metal through recapture and recycling so that it may be available again in the future must not be overlooked; or the value of allowing a person to live a healthy and productive life. These are values which are harder to measure in current terms, but are no less important to creating a truly sustainable business and society.

\subsection{Indicators}

Sustainability can be discussed in terms of three pillars: environment, society and economy [14]. Any consideration of value operating within a sustainable PSS should also incorporate these. At the initial stage of framework development, it is proposed that value within the PSS is judged on a streamlined set of indicators to reduce the information capture that is required. They are proposed to act as a proxy for other impacts within the mobile phone sector. For the purposes of this article, the focus is given to economic and environmental indicators and a new, proposed technological indicator required for the fast moving mobile phone sector.

\section{Environmental}

Global warming potential (GWP) is a well understood environmental impact [15], widely reported in, for example, carbon footprinting [16]. It is proposed as a rough proxy for intensity of resources in the manufacture of components and as part of the consideration of recycling metals within those components. It is recognised that there will be situations where this relationship does not hold.

Water use is also proposed, as this stock cannot be substituted by other materials. Semiconductor manufacture uses significant quantities of water [17] and it is proposed as one of the key planetary boundaries [18]. It is possible to extract data on both the GWP and the quantity of water used from life cycle assessment (LCA) databases, such as ecoinvent 3.1 [19].

An indicator of remaining reserve and consumption is proposed. The use of materials and their remaining availability can be used as a proxy for future sustainability of the metal in question. Further discussion of this is offered later in this article.

\section{Economic}


The price of metals and components is the main driver for recycling, aside from possible regulation of toxic substances [8], in the current business climate. Therefore, price of the metals per given weight and price of components is proposed as an economic indicator. Access to resources is a combination of many factors, but price (albeit perhaps slightly lagging from events) does reflect aspects of availability.

\section{Technological}

A technological indicator must capture the ability of a component to perform its function within the context of a smartphone. These devices are typically comprised of many different components performing different functions, each of which may be measured using multiple different metrics. For example a CPU may be measured by clock speed, bus speed, number of cores, or algorithm optimisation and so on. Collecting all of the data for a good cross comparison between multiple processors becomes an intensive process especially when the factors may carry different weighting for importance. Therefore, it is proposed that price may act as a proxy of the technical capability of the component.

A component such as a CPU will reduce in price as it is superseded by more capable versions, indicating its ability to perform against the backdrop of the average of the products available in that product category. A similar trend may be observed across many other technologies as their specification sheet becomes poorer compared to new products. Furthermore, it is combined with the economic indicator, reducing the need for data collection and price is easily accessible to any consumer or manufacturer, increasing ease of use. For this reason it is proposed for use in this value assessment.

\subsection{Value calculations}

The calculation of value must allow a threshold to be set so that when it is met, an action is triggered. This can be achieved by simply comparing the value at time $t$ against the value at the point of creation of the phone $\left(t_{0}\right)$ :

$$
\text { Value }(t)=\frac{\text { Value of phone }(t)}{\text { Value of phone }\left(t_{0}\right)}
$$

Eq. 2 shows the value of a phone being the product of the components under consideration.

$$
\text { Value of phone }=\prod_{i}\left(\text { Value of } \text { part }_{i}\right)
$$

The equation is given as a product, as opposed to a sum as the value of any one component must have the ability to control the overall value calculation. For example, a component with relatively little value will not contribute significantly to a sum calculation. If the component becomes unable to perform its function and its technological value drops to zero, it will have little impact on the value of the phone even though the phone can no longer perform its function. Therefore, it is necessary to allow the component to control the overall value; in a product, if component value falls to zero, so does that of the phone. The value of the components is then calculated as

Value of $\operatorname{part}_{\mathrm{i}}(t)=\left(G W P_{i}\left(t_{0}\right)\right)\left(H_{2} O_{i}\left(t_{0}\right)\right)\left(r c y_{i}(t)\right)\left(\operatorname{res}_{i}(t)\right)\left(\right.$ price $\left._{\text {Eq. }}(t)\right) x^{i}$

where $G W P_{i}$ is the global warming potential required to create component $i, \mathrm{H}_{2} \mathrm{O}_{i}$ is the water required to create component $i, r c y_{i}$ is the recycling indicator for the metals used in component $i, \operatorname{res}_{i}$ is the resource indicator the metals used in component $i$ and price $_{i}$ is the monetary value of component $i$. The factor $x_{i}$ may be allocated as considered appropriate, but it is proposed that component mass is the best metric. The time of assessment of the different factors within Eq. 3 is different. $\mathrm{GWP}_{i}$ and $\mathrm{H}_{2} \mathrm{O}_{i}$ are assessed at the time of manufacture of the component. These two factors are essentially an indicator of what has gone into making the component. Avoiding replacing the component for as long as possible allows a spread of impact within these categories over a longer period of time, and therefore a net reduction in impact per year of use. The factors $r c y_{i}$, res $_{i}$ and price $_{i}$ should be assessed at the given point in time of value calculation. These in effect represent the value that can be extracted from the components at time $t$.

Eq.4 shows the calculation to derive the $r c y_{i}$ indicator. This acts to show the importance of recycling a metal from an environmental and economic perspective. Again simplicity is the goal of this indicator. Other methods of assessing recyclability tend to focus on the environmental responsibility of recycling, but less the economic advantages [20-22]. Furthermore, other indicators often include efficiency of the recycling system in recovering the metal. For the purposes of a PSS it can be assumed that the collection rate is near $100 \%$, therefore the focus is on the value of recycling the metal itself:

$$
r c y_{i}=\sum_{l}\left(\$ / k g_{l}\right)\left(G W P_{l}\right) y_{l}
$$

where $\$ / \mathrm{kg}_{l}$ is the price per $\mathrm{kg}$ of metal $l, G W P_{l}$ is the global warming potential indicator for metal $l$ and $y_{l}$ is the fraction of metal $l$ by weight in the component. $G W P_{l}$ is expanded as:

$$
G W P_{l}=\left(G W P_{\text {raw }}-G W P_{\text {rec }}\right)
$$

where $G W P_{\text {raw }}$ is the GWP associated with producing one $\mathrm{kg}$ of metal $l$ from virgin ore and $G W P_{\text {rec }}$ is the GWP associated with creating one $\mathrm{kg}$ of metal $l$ from recyclate. The form of the equation prioritises metals that have a large saving in GWP from recycling and cause a large GWP by being produced. If no recycling information is found, $G W P_{\text {rec }}$ may be set to 0 . This simultaneously gives priority to metals which are not recycled and also avoids penalizing metals which are recycled but for which the information is not available.

Eq. 6 shows the res $_{i}$ indicator. This acts as a measure of the pressure on known reserves by current consumption. 


$$
\operatorname{res}_{i}=\sum_{l} \frac{U_{l}}{R_{l}} y_{l}
$$

Where $U_{l}$ is the annual production of metal $l$ and $R_{l}$ is the known reserve of metal $l$ in tons and $y_{l}$ is the fraction of metal $l$ by weight within the component. The indicator uses production as a proxy for consumption. Production data can be readily found within the same publications as reserve [23] and will often reflect consumption of the same metal over a similar period.

\subsection{Incomplete bill of materials}

It is apparent that the consideration of the value of a phone or components is only in terms of weighted fractions of the materials of interest. This presents two options: ascertain the benefit of every material present in a mobile phone, or focus on those which represent the best potential for sustainability, i.e. the metals. These may be recycled indefinitely and cannot be synthesised chemically in the same manner as organic materials.

\subsection{Costs}

Each time a component within the phone is replaced, a cost is incurred. This is defined as a negative impact against each of the indicators, where appropriate. For example, emissions against $G W P_{i}$ and $\mathrm{H}_{2} \mathrm{O}_{i}$ will occur and a monetary expense is created, e.g. through wages. There are not anticipated to be costs associated with the $r e s_{i}, r c y_{i}$ or price $_{i}$ indicators. Therefore, the cost can be calculated as

$$
\text { cost }_{i}=\left(G W P_{m}\right)\left(H_{2} 0_{m}\right)\left(\text { expense }_{m}\right)
$$

where $G W P_{m}$ is the associated emissions, $\mathrm{H}_{2} \mathrm{O}_{m}$ is the water use and expense $e_{m}$ is the monetary costs of replacing the component. It should be noted that the impacts of creating the components themselves are not included in the cost: those are factored into the calculation of value, as outlined in Eq. 2, and double accounting should be avoided where possible.

Upon replacement of a part the value of the phone becomes the subtraction of the value calculated in Eq. 7 from that of Eq. 2.

$$
\begin{aligned}
& \text { Value of phone at point of replacement }= \\
& \prod_{i}\left\{\left(G W P_{i}\right)\left(H_{2} O_{i}\right)\left(\text { rec }_{i}\right)\left(\text { res }_{i}\right)\left(\text { price }_{i}\right)-\left(\text { cost }_{i}\right)\right\}
\end{aligned}
$$

It is clear that upon replacement of the component the cost may keep the value of the phone as a whole below the threshold for replacement. This would indicate that the gain from replacement is not worth the cost of the intervention. In these cases the value of the individual components must be made separately to ascertain their worth in stockpiling for use in other phones. It is entirely possible that a component will never be worth the cost of replacing, and it is here that the value calculation can inform the best development of the PSS for sustainability.
When a component is replaced within the phone, care must be taken to maintain the relative time factors, $t$. All of the components must have a $t_{0}$ set to the moment that they are incorporated into the phone. Therefore, the original components will have a $t_{0}$ set to the time of manufacture, the replacement components will have a different $t_{0}$ set to the time of replacement.

\subsection{Calculations at the decision points}

Value is calculated at each of the decision points within the stocks and flows system, Fig. 1. The factors used to calculate the value at each point do not change, but the form of the calculation will change depending on the particular decision point.

Reuse

If a phone is returned, for whatever reason the first value assessment may determine if it has sufficient residual value to be reused without modification. Those found to be above the threshold may be routed through $f_{3} q$.

\section{Remanufacture}

If found not be to sufficiently valuable for reuse, it can be considered for remanufacture. If the value can be restored sufficiently with replacement of one or more parts, including associated costs, it may be sent round route $f_{1} q$. If not, the phone is sent for disassembly and value assessment, $f_{2} q$. This calculation is the same as that for reuse, except the cost is applied on a component by component basis, therefore, it is a level of disaggregation compared to the reuse assessment.

\section{Stockpile}

Once disassembled the components are analysed for their ability to return the existing stock of phones to a sufficient value to re-enter the stock pool. Again, the equations used are the same as those already presented, only with a different time point of assessment. If the components are deemed insufficient, they are sent for reprocessing, (1$\left.f_{4}\right) f_{2} q$, to recapture the raw materials, otherwise they are sent for stockpiling. Whilst being stockpiled they may be periodically tested for retained value. If components are found to not have enough value they are removed from the stockpile for reprocessing.

\section{Post-stockpile}

Upon exiting the stockpile the components may be analysed for residual value in potential reprocessing, or for export to lower value markets. It is possible that some components will never realise sufficient value via reprocessing to overcome the associated costs and that best extraction of value is through export to lower value markets, even with the associated uncertain disposal routes. The assessment of value at this juncture may be split into two separate equations which can be compared directly against one another. These are shown in Eq. 9 and Eq. 10.

$$
\text { Value in } \mathrm{UK}=\left(\operatorname{rec}_{i}\right)\left(\text { res }_{i}\right)-\left(\operatorname{cost}_{i}\right)
$$




$$
\text { Value export }=\left(G W P_{i}\right)\left(H_{2} \mathrm{O}_{i}\right)\left(\text { price }_{i}\right)-\left(\text { landfill }_{i}\right) \text { Eq. } 10
$$

Where landfill $_{i}$ is the product of the impact from landfill of a component arising against the indicators as outlined previously in this article, much like cost, and the rest of the terms are defined the same as before. The larger value arising from the calculation determines whether the component are exported, $\left(1-f_{5}\right)\left[\left(f_{1}+f_{2} f_{4}\right) q-r_{1} p\right]$, or routed for reprocessing, $f_{5}\left[\left(f_{1}+f_{2} f_{4}\right) q-r_{l} p\right]$.

It is at this decision point that social indicators would be most useful to consider. The loss of components to a low value market with poor recycling may result in a negative social impact. This is either through leaching of toxic substances to landfill [24], informal recycling or recycling with lower environmental standards than the EU [10]. An appropriate proxy for health may be human toxicity potential [15] but even this does not capture the possibilities for benefit that mobile telephony may bring to those markets [5]. These factors must be understood on a case by case basis, and must overcome the current problem of relatively uncontrolled export of electronic waste which occurs even in Europe's highly regulated sector [9].

\subsection{Calculation of initial value}

The calculation of value has been presented as a method of determining the direction of flows between stocks within the PSS. This is a time sensitive calculation, but before it can be made, the value within the phone itself must be understood to know which components or assemblies may be targeted for value extraction. The result of a component value assessment is presented here.

A sample set of components within a phone are modelled to demonstrate the application of value. The phone is modelled as consisting of a subset of components including the main $\mathrm{PCB}$, mounted with processor and memory ICs, the display (LCD), the battery, antenna and the metal case. The component weights and compositions are based upon a Fairphone [25] with supplementary data for PCB [22], battery [26] and LCD [27] composition used where appropriate. The antenna and LCD are assumed to contain a PCB and ICs as part of their construction. Information for GWP and $\mathrm{H}_{2} \mathrm{O}$ indicators is taken from the ecoinvent 3.1 database accessed via SimaPro LCA software, PRé Consultants. Data on resources is sourced from Minerals and Commodity Summaries 2015 [23]. Due to volatility of price of materials, these were accessed at time of writing from a variety of online sources. The value is calculated as a snapshot at the point of manufacture of the phone, therefore does not consider how price of components may vary with time.

All of the metals found in the literature relating to the components are considered: copper, gold, lithium, cobalt, silver, indium, stainless steel, iron, chromium, nickel, manganese, aluminium, lead, tin, zinc, molybdenum, antimony and palladium.

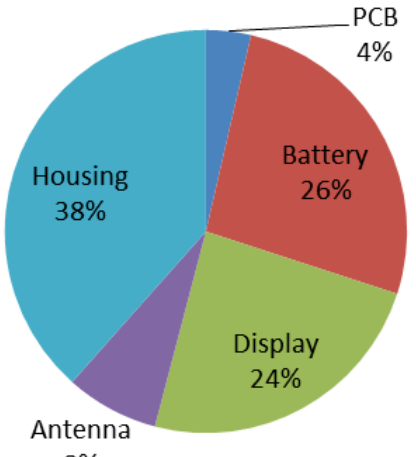

$8 \%$

Fig. 2 Component mass fraction within the example phone.

Fig. 2 shows the phone by component mass. The mass includes both metals and non-metals. It is shown that the housing contains the majority of phone mass $(38.4 \%)$ followed by the battery (26.4\%), with the PCB the lightest at $4 \%$.

Fig. 3 shows the value of the components. It is clear that the PCB dominates the value, taking over $84 \%$ of the total. Most of the remainder is taken by the antenna and display. The housing no longer contributes any significant value to the phone at only $8.2 \times 10^{-5} \%$.

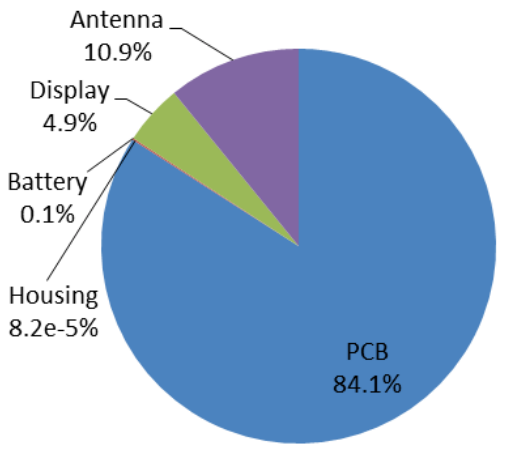

Fig. 3 Percentage value of the components.

The value of the phone is dominated by the precious metals it contains; gold, silver and palladium. Despite the tiny combined content of those metals within the phone, a total of $0.032 \%$, their high price per $\mathrm{kg}(\mathrm{Au}=\$ 42279$, $\mathrm{Ag}=\$ 584, \mathrm{Pd}=\$ 8096$ at time of writing) and large GWP for extracting virgin material $(\mathrm{Au}=17100, \mathrm{Ag}=485$, $\mathrm{Pd}=8613 \mathrm{kgCO}_{2}$-eq $/ \mathrm{kg}$ [19]), as opposed to recycling, makes their contribution to the net value the largest. Any PCB within the phone has all three of these metals, therefore, any component containing a PCB has an increased total value both economically and environmentally. By contrast, the housing becomes negligible due to the low price and ready availability of the steel from which it is made.

The calculation shows that in the design of the PSS, PCB containing components would be a priority for reuse wherever possible and the flows should be directed 
accordingly between the stocks to achieve this. This is especially true at the time of removal from the stockpile, when the PCB would always be better reprocessed for the materials than exported to a lower value market.

The design of the phone itself should be to maximise the opportunity for reuse of the PCB where at all possible. This may be achieved, for example, by design of the architecture of the circuitry to allow for the efficient replacement of components with long lifetimes.

\section{CONCLUSION}

The stocks and flows model for a circular economy has been discussed for its ability to identify decision points which must be addressed in order to direct flows through the most appropriate loops for sustainability. These decision points require a metric which can be applied to the value contained within a mobile phone so that thresholds may be set in order to ensure that the value is extracted at an appropriate time. However, mobile phones are made up of multiple components each with a different potential or actual lifetime. In the current business model, phones are often replaced before the components are truly obsolete [28], or can no longer perform a function. In consideration of the components, they may have a lifetime which is dictated by loss of performance, for example the battery which will degrade over a predictable period of time [29], or by technological advance, or even through user interference, for example accidental damage to a display. Each of the lifetimes will have a different predictability of the moment when replacement is needed.

Building upon the prior work of the authors [13 \& 28] we suggest that such a PSS could be developed in which components with low emotional value and that require regular upgrade, the internal electronic components, could be owned by the business and leased as part of the service to the consumer. By the handset being provided by the PSS supplier as part of the service, this allows for control and retention of the valuable metals within the phone and the best opportunity for extraction of the value from the phone at each point within the PSS.

Within this suggested PSS, the consumer has two touchpoints; during purchase (for example, e-commerce shopping, traditional bricks-and-mortar retail, local franchises or independent community upgrade shops) and during servicing. A servicing operation is triggered when a consumer requires or desires a hardware upgrade (due to one, or a combination of reasons for obsolescence; absolute, functional, technological, societal etc. [30-32]) or if there is a breaching of a given operational threshold for the phone as a whole, or a component within it (as defined by the service contract). By returning the phones for regular upgrade, the service will satiate consumer demand for the latest hardware whilst also enabling businesses to retain and assess components for value individually, thereby defining the treatment that the components will undergo within the backroom activities of the PSS and facilitating efficient metal use and recovery.

Therefore, the components must be assigned a time varying value which can be measured against a threshold, the reduction below which will trigger an interaction between the service provider and the consumer to bring their service level back to required specification. This creates an interaction of the consumer with the PSS in which the consumer returns the phone to a suitable servicing platform and the phone is examined with internal hardware (such as the deteriorated battery) and software upgrades installed as requested or as necessitated.

The refurbished phone is returned to the customer, thereby maintaining its optimum performance, whilst also ensuring the return of handsets and/or components to the business for further treatment; stockpiling or reprocessing as appropriate. In order to understand when to extract the best value possible at each point within the PSS this article has explored the concept of quantitative value incorporating the economic and environmental pillars of sustainability. The addition of a new technological pillar is also proposed in order to assess the value of a mobile phone in terms of its ability to operate at a required performance level.

The value of a simplified phone is calculated. It is shown that precious metals, gold, silver and palladium, dominate the value despite being only a tiny fraction of the total mass. In this example, they are predominantly found within PCBs and components containing them. The dominance of value is due to their high price per kilogram and the large GWP associated with extracting them from the ground compared to recycling. The high value of the PCB highlights the need to ensure that these components are used for as long as possible and that when considered for disassembly, they may be removed from the phone with minimal intervention.

\section{ACKNOWLEDGEMENTS}

The authors wish to thank the Engineering and Physical Sciences Research Council (EPSRC) for their financial support of this work as part of the CLEVER project (Closed Loop Emotionally Valuable E-waste Recovery), funded under grant number ep/k026380/1. The authors confirm that data underlying the findings are available without restriction. Details of the data and how to request access are available from the University of Surrey repository: http://epubs.surrey.ac.uk/id/eprint/808005

\section{REFERENCES}

[1] Oguchi M, Murakami S, Sakanakura H, Kida A, Kameya T (2011) A preliminary categorization of end-oflife electrical and electronic equipment as secondary metal resources. Waste Manag 31:2150-2160 
[2] Tanskanen P (2013) Management and recycling of electronic waste. Acta Materialia 61:1001-1011

[3] Ongondo FO, Williams ID (2011) Greening academia: Use and disposal of mobile phones among university students. Waste Manag 31:1617-1634

[4] Geyer R, Blass VD (2010) The economics of cell phones reuse and recycling. Int $\mathrm{J}$ Adv Manuf Technol 47:515-525

[5] Osibanjo O, Nnorom IC (2008) Material flows of mobile phones and accessories in Nigeria: Environmental implications and sound end-of-life management options. Environ Impact Assess Rev 28:198-213

[6] Navazo JMV, Méndez GV, Peiró LT (2014) Material flow analysis and energy requirements of mobile phone material recovery processes. Int $\mathrm{J}$ Life Cycle Assess 19:567-579

[7] Chancerel P, Rotter VS (2009) Assessing the management of small waste electrical and electronic equipment through substance flow analysis - The example of gold in Germany and the USA. IEEE Int Symp on Sustain Syst and Technol 2009

[8] Waste Electrical and Electronic Equipment Directive 2012/19/EU.

[9] Huisman J et al (2007) Waste electrical and electronic equipment (WEEE) final report. United Nations University, Bonn, Germany.

[10] Wong MH, Wu SC, Deng WJ, Yu XZ, Luo Q, Leung AOW, Wong CSC, Luksemburg WJ, Wong AS (2007) Export of toxic chemicals - A review of the case of uncontrolled electronic-waste recycling. Environ Pollut 149:131-140

[11] Stahel WR (2010) The performance economy, 2nd edn. Palgrave MacMillan, Basingstoke, UK

[12] Manzini E, Vezzoli C (2003). A strategic design approach to develop sustainable product service systems: Examples taken from the 'Environmentally Friendly Innovation' Italian prize. J Clean Prod 11:8:851-857.

[13] Wilson GT, Bridgens B, Hobson K, Lee J, Lilley D, Scott JL, Suckling J (2015) Single product, multi-lifetime components: challenges for Product-Service System development. PLATE Conference 2015.

[14] Bhamra TA, Lofthouse VA (2007) Design for sustainability a practical approach, Gower Publishing Limited.

[15] Goedkoop MJ, Heijungs R, Huijbregts M, Schryver, A De, Struijs J, VanZelm R (2009) ReCiPe 2008, A life cycle impact assessment method which comprises harmonised category indicators at the midpoint and endpoint level. 1st edn. Report 1: Characterisation.

[16] PAS 2050:2008 Specification for the assessment of the life cycle greenhouse gas emission of goods and services.
[17] Williams ED, Ayres RU, Heller M (2002) The 1.7 kilogram microchip: Energy and material use in the production of semiconductor devices. Environ Sci and Technol 36:5504-5510

[18] Rockström J et al (2009) A safe operating space for humanity. Nature 461:472-475

[19] ecoinvent v3.1, ecoinvent, Zurich, Switzerland. http://www.ecoinvent.ch/

[20] Legarth JB, Alting L, Danzer B, Tartler D, Brodersen K, Scheller H, Feldmann K (1995) A new strategy in recycling of printed circuit boards. Circuit World 21:10-15

[21] Huisman J, Boks CB, Stevels ALN (2003) Quotes for environmentally weighted recyclability (QWERTY): Concept of describing product recyclability in terms of environmental value. Int J Prod Res 41:3649-3665

[22] Le H-L, Yamasue E, Okumura H, Ishihara KN (2013) MEMRECS - A sustainable view for metal recycling from waste printed circuit boards. J Environ Prot 4:803-810

[23] United States Geological Survey (2015) Mineral commodity summaries 2015.

[24] Kiddee P, Naidu R, Wong MH (2013) Metals and polybrominated dephenyl ethers leaching from electronic waste in simulated landfills. J Hazard Mater 252-253:243249

[25] Guvendik M (2014) From Smartphone to Futurephone: Assessing the Environmental Impacts of Different Circular Economy Scenarios of a Smartphone Using LCA. MSc thesis Industrial Ecology, Delft University of Technology and Leiden University.

[26] Castillo S, Ansart F, Laberty-Robert C, Portal J (2002) Advances in the recovering of spent lithium battery compounds. J Power Sources 113:247-254

[27] Savvilotidou V, Hahladakis JN, Gidarakos E (2014) Determination of toxic metals in discarded liquid crystal displays (LCD). Resour, Conserv and Recycl 92:108-115

[28] Suckling J, Lee J (2015) Redefining scope: The true environmental impact of smartphones? Int J Life Cycle Assess DOI: 10.1007/s11367-015-0909-4

[29] Takeno K, Ichimura M, Takano K, Kamaki J (2005) Influence of cycle capacity deterioration and storage capacity deterioration on li-ion batteries used in mobile phones. J Power Source 142:298-305

[30] Cooper T (2004). Inadequate life? Evidence of consumer attitudes to product obsolescence. J Consumer Policy 27:421-449.

[31] Packard V (1967). The waste makers: Penguin.

[32] van Nes N, Cramer J (2006) Product lifetime optimization: a challenging strategy towards more sustainable consumption patterns. J Clean Prod 14:13071318. 